\title{
Risk Perception, Choice of Source and Treatment Decision: Exploring Water Consumption Behaviour in Darjeeling, India
}

\author{
Pravesh Tamang*† and Sebak Jana** \\ *Department of Economics, Presidency University, Kolkata, India \\ **Department of Economics, Vidyasagar University, Midnapore, India \\ †Corresponding author: Pravesh Tamang; singarpravesh@gmail.com
}

\author{
Nat. Env. \& Poll. Tech. \\ Website: www.neptjournal.com \\ Received: 08-10-2019 \\ Revised: 06-11-2019 \\ Accepted: 11-12-2019 \\ Key Words: \\ Water consumption \\ Water treatment \\ Environmental economics \\ Bivariate probit
}

\begin{abstract}
Using a unique dataset of 524 households from an urban hill town of Darjeeling in India, this study addresses two key issues of (a) determining the drivers of risk perception from water use, and (b) understanding whether water treatment decisions and choice of water sources are jointly made by the households. The results from probit model show that the age of the head, perception of the aesthetic qualities of water (odour and colour), education level of the head, the volume of improved water used, water treatment decision and expenditure on the water are the significant drivers of risk perception. The results of a rare investigation on the likelihood of the joint decision of treating water and choice of water source show that these decisions are indeed jointly made in the study area. Households decision to treat water from an unimproved source and the choice of improved water can be seen as substitutes.
\end{abstract}

\section{INTRODUCTION}

Water and sanitation are very crucial to the survival of people and the planet, and hence at the core of sustainable development. There have been advances in the use of 'improved sanitation facilities' (from 59\% in 2000 to $68 \%$ in 2015) and 'improved water sources' (from $82 \%$ in 2000 to $91 \%$ in 2015) at the global level (United Nations 2016). However, in developing countries, not all 'improved sources' used are safe, and in 2012, an estimated 1.8 billion people were exposed to drinking water source contamination. In addition, the figures which pertain to the number of people having access to safe water seem to be overestimated as recent studies have shown that having access to 'improved sources' does not necessarily mean access to 'safe water' (Bain et al. 2014, Onda et al. 2012). Lack of safe water, sanitation, and hygiene in most of the developing countries led to $88 \%$ of deaths from diarrheal diseases, with a majority of them being children under the age of 5 (UNICEF 2008). In India, an estimated $38 \%$ of all deaths are attributable to diarrhoea (Walker et al. 2012).

The risks from water contamination, which emerge from sources around watersheds, raw sewage and industrial waste, are more visible in a developing country like India. Making water consumption decisions in such a situation demands reliance on sensory data or perceptions, such as the sight of a dead cow or the smell of rancid water (Crampton \& Ragusa 2016). In those cases where contamination cannot be directly observed or perceived, individuals may have to rely on municipal reports on water quality. However, such information has not been easily available or updated, and also not easily understood by an average consumer (Crampton 2014).

Therefore, it becomes important that individuals rely on the personal judgement of water attributes to determine potential risks. Such attributes may include colour (how the water looks), taste, and smell of water (Crampton \& Ragusa 2016). An alternative to this would be to 'trust' that the water providing agency is providing water that adequately addresses all the risks, and thus influences all the stakeholders (Serveiss 2002, Sterling et al. 2014) which is very likely to happen in the municipalities of India, and in Darjeeling (our study area) in particular. This could be so because citizens, who form a vital component of stakeholders, have little or no public discourse on the water quality. Such lack of public discourse is evident in developed nations like Australia and New Zealand too (Crampton \& Ragusa 2016).

Studies which identify factors that affect risk perception related to water perception are still scarce and their findings being not conclusive (Onjala et al. 2014). Some related studies have found that perceived odour and taste of water (Jardine et al. 1999, Nauges \& Berg 2009), the perceived taste of water and its related source (Levallois et al. 1999), age, income, and distance to the water treatment facility (Turgeon at al. 2004) to be the major drivers of risk perception. 
Darjeeling is an urban hill town and a very popular tourist destination in north-eastern India and faces many issues in water services provided by the Darjeeling municipality. Lack of safe drinking water and sanitation services has added woes to the public health which often become more acute during the summer tourist season (Mell \& Sturzaker 2014). The major sources of water contamination in the region are the unsafe biological matter and runoff of solid wastes (Rai 2011). Exposure to such untreated water leads to various water-related diseases such as stomach infection and typhoid. Typhoid was the third most reported disease in Darjeeling in the year 2003, and in the same year, less than $50 \%$ had access to safe water and sanitation (Sharma et al. 2009). The Darjeeling municipality was established in 1850 (considered to be one of the oldest municipalities in India) and the comprehensive water infrastructure laid during 19101930 for a population of 10,000 . About $95 \%$ of the existing pipeline and valves were laid in 1930, and the infrastructure is in great need for renovation and restructuring. Out of 21,782 households in 32 wards of the town, only 2689 households (i.e. 12\%) have municipal water connections and pay INR 500.00 annually as water bill to the municipality (Tamang \& Jana 2017b).

The number of studies related to the perception of risk related to water consumption by households in developing countries is not much as per our knowledge. And in case of Darjeeling, this is the first effort to understand the issues of risk perception from water use and treatment decisions associated with the source of water that the households use. This study shall fill this gap and contribute to the literature by providing answers to the following questions; (a) what are the various drivers of risk perception from water use? (b) are the choice of water source (improved or unimproved source in this case) and a decision to treat water jointly made?

\section{MATERIALS AND METHODS}

\section{Data}

The data for the study come from a primary survey of households in Darjeeling town conducted in the year 2014. A pilot survey followed by a group discussion and focus group interviews with the local members selected at random were conducted before drafting the final questionnaire. From this preliminary analysis, we could get more insights on the various sources of water predominantly used in the neighbourhood, some of the water-related diseases that affected in the recent past, and their water treatment behaviour. The field investigators, who were the students from Darjeeling Government College, were trained by giving classes, conducting mock interviews and group discussions. This was an advantage because they could speak the local language and thus were in a better and comfortable position in conducting the survey. The random sample consisted of 524 households from the 32 wards of the town.

The questionnaire was divided into four sections. The first section consisted of questions on the socio-economic and demographic characteristics such as household ID, name of the respondent, relationship with the head, gender, age, education level, marital status, etc. The second section had questions about household characteristics such as type of residence, ownership, number of rooms, etc. The third section consisted of questions on health and hygiene. Questions were mainly based on the incidence of water-related diseases (diarrhoea, gastroenteritis, eye diseases, cholera, vomiting, blood in mucus or faeces, typhoid, and malaria), different kinds of toilet facilities used, hygiene behaviour, etc. The fourth and final section had questions about the different sources of water currently used by the households, the volume of water collected, perceived water quality (taste, odour and colour), expenditure on water, water treatment behaviour, etc.

\section{Risk Perception}

The first objective of the study is to determine the different drivers of risk perception related to water consumption. A probit model is used for this analysis. The response variable is an indicator of perceived health risk from water consumption from various water sources. Initially, the respondents answered whether they perceived no risk $(=1)$, low risk $(=2)$, or high risk (=3) from the water they consume from various sources. Risk perception is defined as an individual's intuitive risk judgement (based on aesthetic and non-aesthetic qualities) about drinking water (Anadu \& Harding 2000). Therefore, the study also considered the aesthetic qualities (taste, colour, and odour) of water as the elements, and the nature of risk described to the respondents was about the various water-related diseases (included in the third section of the questionnaire and mentioned earlier) that could affect the households.

However, it was found that no risk $(=1)$ responses were only 7 out of 524 . Therefore, this was merged with the low risk (=2) option. This led us to code this response variable as a binary ( $0=$ low risk, $1=$ high risk $)$ contrary to the ordinal specification in the questionnaire. The explanatory variables, which influence health risk perception, and are used in the analysis include the perception of water (taste, colour, and odour), age of the head of the household, education level of the head (primary, secondary, and graduate and above), water treatment behaviour (treat or do not treat), monthly expenditure on water (on all kinds of water sources), and water source (improved or unimproved source). 
Based on the classification of water sources by the Joint Monitoring Programme, WHO and UNCF, piped water into dwelling, piped water in the yard, public standpipe and rainwater have been grouped under improved water sources; and unprotected spring, and water truck and private vendor are grouped under unimproved water sources (United Nations Children Fund \& World Health Organisation 2017). According to the Joint Monitoring Programme, WHO and $\mathrm{UNCF}$ - "An improved drinking-water source is defined as one that, by nature of its construction or through active intervention, is protected from outside contamination, in particular from contamination with the faecal matter" (WHO \& UNICEF 2012).

Following Wooldridge (2012), the econometric model specification of risk perception is given as follows;

$$
y^{*}=\beta_{0}+x \beta+e, \quad y=\left\{\begin{array}{c}
1, \text { if } y^{*}>0 \\
0, \text { if } y^{*} \leq 0
\end{array}\right\}
$$

where, $e \sim N(0,1), y^{*}$ is the unobserved latent variable, $y$ indicates the level of risk (low risk $=0$, and high risk $=1$ ), $x$ denotes the vector of explanatory variables described earlier.

\section{Household's Decision to Treat Water}

The second objective of this paper is to see if a higher perceived risk leads to a higher probability to treat water before drinking it. Drinking water has different sources and the decision to treat or not to treat water before drinking is likely not to be independent of the choice of the water source (Onjala et al. 2014). With this assumption of simultaneous nature of the decision about water source and water treatment, and following Nauges \& Berg (2009), a bivariate probit model with the following specification is derived;

$$
\begin{gathered}
s^{*}=z_{1}{ }^{\prime} \gamma_{1}+e_{1} ; s=1 \text { if } s^{*}>0, s=0, \text { otherwise } \\
t^{*}=z_{2}{ }^{\prime} \gamma_{2}+e_{2} ; y=1 \text { if } t^{*}>0, t=0, \text { otherwise }
\end{gathered}
$$

Here, $e_{1}$ and $e_{2} \sim$ Bivariate Normal (BVN), $s$ is the choice of using an improved water source, $t$ is the decision to treat water before drinking, $s^{*}$ and $t^{*}$ are the two latent variables, $z_{1}$ and $z_{2}$ are the vectors of explanatory variables. In equation (2), the two latent variables $s^{*}$ and $t^{*}$ are not observed, but the variables $s$ and $t$, which indicates the choice of the water source by a household and their decision to treat or not to treat before drinking it are observed. Therefore, the variable $s$ indicates whether the household used an improved or unimproved source of water. Thus, equation (2) considers the joint probability that households choose water either from an improved or an unimproved source $(s)$, and treat water before drinking it $(t)$.

It is assumed, following Nauges \& Berg (2009), that the explanatory factors are the same in both equations, i.e. $z_{1}=$ $z_{2}$. It is also important to see that if the error terms $e_{1}$ and $e_{2}$ are correlated (i.e. $\rho \neq 0$ ). The likelihood ratio test is used to test the null hypothesis that $\rho=0$. This statistic is used to test for the absence of correlation between the two sets of probit equations. Under the null hypothesis that $\square=0$, the model consists of independent probit equations, which can be estimated separately (Greene 2012).

The variable $s$ (the choice of water source) takes the values 0 if the source is unimproved and 1 if it is an improved source. Similarly, $t$ takes the values 1 and 0 if a household treats and does not treat water respectively. The other explanatory variables used in the model are the age of the head, whether the head is female, education level of the head (primary, secondary, graduate and above), income category (below INR 10000, INR 10000 to 50000, and above 50000), employment status of the head, and the number of children below the age of 5 . The employment status of the head variable had five levels (Table 1), however, because of the low number of observations in the casual, informal and unemployed levels, they were grouped under 'informal' employment. Hence, the employment status variable used in the bivariate model consists of three levels; informal, government employee and retired.

\section{RESULTS}

The description and descriptive statistics of the variables used in the analysis are presented in Table 1. It can be seen that the median age of the head of the sample households is 47 years with above-average higher educational attainments (in fact, there were no illiterate heads in the sample), and about $60 \%$ of the households used unimproved water source. As mentioned earlier, the households were asked whether they perceived "no risk", "low risk" or "high risk" from the water that they consume. The number of responses for "no risk" was only seven, so this option was merged with the "low risk" option. Therefore, from Table 1 it can be seen that all the households perceived risk from the water consumption, but the level of risk (low risk $=47.9 \%$, high risk $=52.1 \%$ ) seemed to be almost equally weighted. In terms of the aesthetic qualities of water in terms of odour, colour and taste, the households had varied responses.

A majority of the households ( $92 \%$ ) perceive water to have a good odour, but at the same time, about $86 \%$ seem to be not satisfied with the colour of the water. However, in terms of perceived taste of water, the households are almost equally weighted. In the study, "bad colour" implied that water was turbid with suspended particles like mud sediments and waste particles. The turbidity of water could possibly be because of the illegal tapping along the distribution line which exposes the pipelines to sediments from the soil and other waste particles when the pipelines pass through roads and drains. Another reason could be because $60 \%$ of the 
Table 1: Description and descriptive statistics of the variables used (Sample $=524$ ).

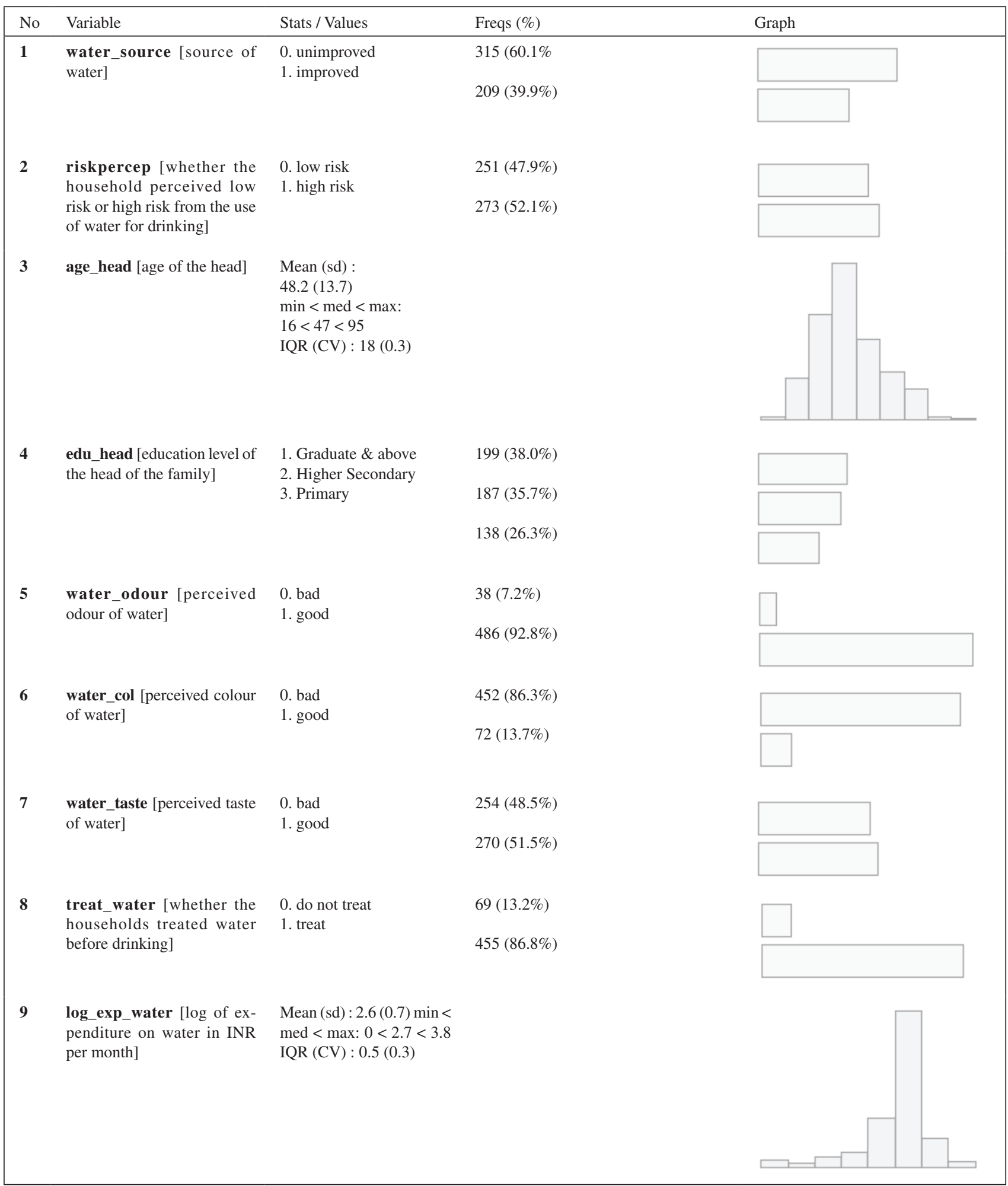


10 vol [volume of water collected in litres per day]

11 femalehead [whether the head was female]

1. yes

Mean (sd)

537 (917)

$\min <\operatorname{med}<\max$ :

$0<175<8000$

IQR $(\mathrm{CV})$ :

$520(1.7)$

0. no

1. yes

1. Below 10,000

2. $10,000-50,000$

3. Above 50,000

$163(31.1 \%)$

$91(17.4 \%)$

$447(85.3 \%)$

0 . no

$77(14.7 \%)$ water related disease in the last six months]

14 emp_head [employment status of the head of the family]

1. Casual Employee 2.

Govt Employee

3. Informal

4. Retired

5. Unemployed

$446(85.1 \%)$

$78(14.9 \%)$

$270(51.5 \%)$

$76(14.5 \%)$

$122(23.3 \%)$

$65(12.4 \%)$

$197(37.6 \%)$

$64(12.2 \%)$

Mean (sd): $\quad 0$

$0.1(0.4) \quad$ :

$\min <\operatorname{med}<\max : \quad 472(90.1 \%)$

$0<0<3$

IQR (CV): 0 (3.2)

1

$8(1.5 \%)$

3

$1(0.2 \%)$

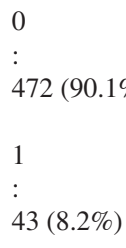

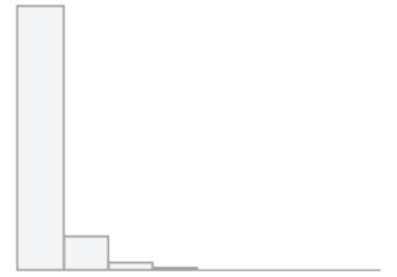
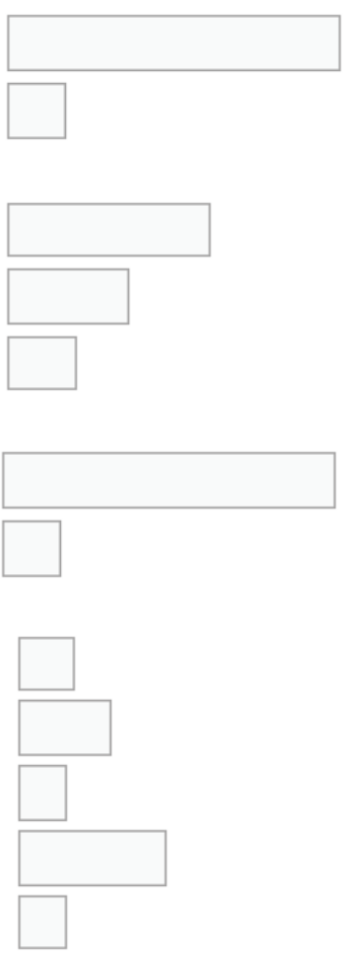

Source: Author's computation from survey data. 
sample households collect water from unimproved sources and there is a high chance that they end up with bad aesthetics in water.

The median volume of water collected from improved sources (piped water into dwelling, piped water in the yard, public standpipe, and rainwater) is 175 litres per month, and irrespective of the source of water, about $87 \%$ of the households treat water (i.e. either boil, filter, add chlorine or stain) before drinking. This means that for an average household of 5 members, the water availability is a meagre 8.75 litres per capita per day, which is far below the recommended per capita water availability of 200 litres per day for municipal households in India and the per capita availability of 20 litres per capita per day reported in a water and waste disposal study commissioned by Darjeeling Municipality in 2002. An important aspect of water scarcity could be attributed to the burgeoning population of the town.

The majority of the sample households $(51 \%)$ had incomes below INR 10,000. Most of the heads were retired personnel (about 38\% and a majority of them had retired from the Indian Army, Gorkha Regiment) and others working as government employees (23.3\%) and the rest working in the informal sector (shops, vendors, etc.) and casual employees (mostly being casual teachers in schools and colleges). There were a very small number of families with children below the age of 5 (90\% of the families had no child below the age of 5), and only $15 \%$ of the households report the prevalence of water-related diseases (like diarrhoea, gastroenteritis, eye diseases, vomiting, typhoid, etc.) is among the family members during the last six months.
Table 2 reports the results from the probit regression model with perceived health risk as to the dependent variable. The results find that the significant drivers of risk perception are the age of the head, education level of the head, perception of the aesthetic qualities of water, the volume of improved water used, water treatment decision, and expenditure on water. All the coefficients of the variables have expected signs and are statistically significant at $1 \%, 5 \%$ and $10 \%$ levels of significance.

It can be inferred that the older heads in the sample are more likely to report higher risks from water that they use. Heads of the households with primary and secondary levels of education are less likely to report higher risk as compared to the graduates or those having even higher educational attainment, and this probability increases for lower levels of education (secondary $-16 \%$ to primary $-19 \%$ ). The households having a "good" perception about the aesthetic qualities of water (odour and colour) are less likely to report "high risk" from water use. These results are similar to the findings of (Jardine et al. 1999, Levallois et al. 1999, Nauges \& Berg 2009).

If the households collect water from an unimproved source, they are more likely to report higher risks. However, if they collect water from an improved source, they are less likely to report high risks, but this probability is very low $(0.01 \%)$. And also, households with higher expenditure on water (per month) are more likely to report higher risks, as the higher volumes of water collected are usually procured from water vendors (sold in trucks and carts) which are unimproved sources.

Table 2: Results of the probit model with dependent variable = risk perception.

\begin{tabular}{|c|c|c|c|c|}
\hline & Estimate & & Marginal Effects & \\
\hline age_head & $0.007552(0.004303)$ & $*$ & $0.003005(0.00171)$ & $*$ \\
\hline \multicolumn{5}{|c|}{ Education of the head (base $=$ Graduate) } \\
\hline edu_headPrimary & $-0.4848(0.1369)$ & $* * *$ & $-0.191539(0.053060)$ & $* * *$ \\
\hline edu_headSecondary & $-0.4054(0.1506)$ & $* * *$ & $-0.160586(0.058708)$ & $* * *$ \\
\hline \multicolumn{5}{|c|}{ Perception about water quality } \\
\hline water_odorgood & $-1.931(0.3759)$ & $* * *$ & $-0.495754(0.037973)$ & $* * *$ \\
\hline water_colgood & $-0.5136(0.2346)$ & $* *$ & $-0.201384(0.088055)$ & $* *$ \\
\hline water_tastegood & $-0.1297(0.1182)$ & & $-0.0515712(0.046901)$ & \\
\hline treat_watertreat & $-0.2569(0.1741)$ & & $-0.1007971(0.06687608)$ & \\
\hline log_exp_water & $0.2266(0.09118)$ & $* *$ & $0.0901565(0.03628202)$ & $* *$ \\
\hline water_sourceunimproved & $0.2287(0.12)$ & $*$ & $0.0906404(0.04725925)$ & $*$ \\
\hline vol & $-0.0002686(0.00007776)$ & $* * *$ & $-0.000102(0.000030968)$ & $* * *$ \\
\hline (Intercept) & $1.607(0.5175)$ & $* * *$ & & \\
\hline
\end{tabular}

$* \mathrm{p}<0.1, * * \mathrm{p}<0.05, * * * \mathrm{p}<0.01$ 
It is also important to understand that since only 2,689 out of $21,872(12 \%)$ of the households have a municipal connection, the issue of multiple illegal tapping of water pipes along the course of the path has become rampant in the town (Tamang \& Jana 2017b). This implies that more than 2,689 households (and more than $39.9 \%$ of the sample households in this study) draw upon municipal water, albeit through unauthorised means. This would explain the perception of water quality as being good and the low prevalence of water-related diseases.

The second objective of the paper is to understand whether the decision to treat water and the choice of water source are jointly made. Table 3 summarizes the results from a bivariate probit regression. The coefficients for improved water source and the decision to treat water along with the marginal effects of the joint probability that the households choose improved water source and also treat water are reported in the table. The likelihood ratio test which is used to test the null hypothesis that $\rho=0$ is rejected (see Table 3 ), and we can conclude that there is a negative association $(\rho=-0.2)$ among the choice of water source and treatment decision. This means that households would treat water from an unimproved source and do not treat those from an improved source. Therefore, treating water from unimproved sources and the choice of the improved water source can be seen as substitutes (Onjala et al. 2014).

From the marginal effects reported in Table 3, we can infer that households with female heads are less likely to treat water or chose an improved source as their main source of drinking water. Higher educational attainment of the head is also a positive and an important factor in the joint decision of water treatment and choice of the improved water source as compared to the lower levels (base = primary). However, this cannot be confirmed at the graduate and higher level of educational attainment as the estimate is not statistically significant but the direction of change is still positive. Similarly, households having a history of water-related diseases during the past six months and those who perceive water to be of high risk, increase the likelihood of having an improved water source and treating water by $9 \%$ and $4 \%$ respectively. This is also seen to be true with those households who have children of age less than 5 .

\section{DISCUSSION}

Using a unique dataset of 524 households from an urban hill town of Darjeeling in India, this study addresses two key issues of (a) determining the drivers of risk perception from water use, and (b) understanding whether water treatment

Table 3: Bivariate probit model for the joint decision of treating water and choice of the water source.

\begin{tabular}{|c|c|c|c|c|c|c|}
\hline & Improved water source & & Water is treated & & Marginal Effects & \\
\hline agehead & $-0.001863(0.0043146)$ & & $0.0025882(0.0055865)$ & & $0.0003007(0.0005341)$ & \\
\hline femalehead & $0.2917604(0.175605)$ & $*$ & $-0.7947914(0.280762)$ & $* * *$ & $-0.0810337(0.0264772)$ & $* *$ \\
\hline \multicolumn{7}{|c|}{ Education of the head (base $=$ Primary) } \\
\hline secondary & $-0.1358546(0.1524655)$ & & $0.3498633(0.2077779)$ & $*$ & $0.0359699(0.0198315)$ & $*$ \\
\hline graduate_and_above & $-0.2870002(0.1590904)$ & $*$ & $0.1946223(0.2150053)$ & & $0.0285324(0.0204698)$ & \\
\hline 10,000 to 50,000 & $0.1995249(0.1378145)$ & & $-0.2205172(0.1865709)$ & & $-0.027263(0.0178276)$ & \\
\hline above 50,000 & $0.0115453(0.167218)$ & & $0.2933057(0.2104085)$ & & $0.0250984(0.0203028)$ & \\
\hline disease_yes & $-0.6650379(0.1630546)$ & $* * *$ & $0.748401(0.1865748)$ & $* * *$ & $0.092038(0.0203936)$ & $* * *$ \\
\hline risk_perception & $-0.364791(0.116668)$ & $* * *$ & $0.3066869(0.1561886)$ & $*$ & $0.0414356(0.015255)$ & $* *$ \\
\hline \multicolumn{7}{|c|}{ Employment status of the head (base $=$ Informal) } \\
\hline Retired & $0.2113224(0.1380626)$ & & $0.2542488(0.1768716)$ & & $0.0136409(0.0171066)$ & \\
\hline Govt. employee & $0.0961065(0.1593869)$ & & $0.2328213(0.2011365)$ & & $0.0164179(0.0192891)$ & \\
\hline child & $-0.2118614(0.1445517)$ & & $0.3030059(0.1784118)$ & $*$ & $0.0349499(0.0174268)$ & $* *$ \\
\hline _cons & $0.5760646(0.3292189)$ & $*$ & $-2.346801(0.4689399)$ & $* * *$ & & \\
\hline /athrho & $-0.2066754(0.0989003)$ & & & & & \\
\hline rho & $-0.2037821(0.0947932)$ & & & & & \\
\hline
\end{tabular}

Likelihood-ratio test of $\mathrm{rho}=0: \quad$ chi2 $(1)=4.41739 \quad$ Prob $>$ chi $2=0.0356$ 
decisions and choice of water sources are jointly made by the households. The results from probit model show that the age of the head, perception of the aesthetic qualities of water (odour and colour), education level of the head, the volume of improved water used, water treatment decision and expenditure on the water are the significant drivers of risk perception. The results of a rare investigation on the likelihood of the joint decision of treating water and choice of water source show that these decisions are indeed jointly made in the study area. Households decision to treat water from an unimproved source and the choice of improved water can be seen as substitutes.

An important implication of the study is that improving the aesthetics of water (odour and colour) is certainly going to change the risk perception of people. At present, there is just one sand and gravel filtration plant in Darjeeling (located in Jorebunglow at a distance of $8 \mathrm{~km}$ from the town), that filters the water before it is supplied to the town. However, during the course of the path, there are many illegal tappings, pipes passing through garbage dumping areas, which increase the chances of the deterioration of the aesthetics of water even after it is filtered (Tamang \& Jana 2017a). Increasing the number of filtration plants would indeed help improve the aesthetics of water. Also, the Darjeeling municipality should share water quality test reports and necessary information with the public at regular intervals.

The households in the region have a high willingness to pay (WTP) for improved water services (Tamang \& Jana 2017b), and we also see that treating water and choosing improved water are substitutes, which implies that policies should be aimed at increasing the number of piped connections which is at a low of $12 \%$.

\section{REFERENCES}

Anadu, E. and Harding, A. 2000. Risk perception and bottle water use. Journal of the American Water Works Association, 92(11): 82-92.

Bain, R., Cronk, R., Wright, J., Yang, H. and Slaymaker, T. 2014. Fecal contamination of drinking-water in Low- and Middle-Income Countries: A systematic review and meta-analysis. PLoS Med, 11(5), p.e1001644.

Crampton, A. 2014. Water, an essential resource and potential health risk! rural perceptions, awareness and knowledge of health risks. Retrieved from https://researchoutput.csu.edu.au/en/publications/water-an-essential-resource-and-potential-health-risk-rural-perce

Crampton, A. and Ragusa, A. 2016. Exploring perceptions and behaviors about drinking water in Australia and New Zealand: Is it risky to drink water, when and why? Hydrology, 3(1): 8.

Greene, W. H. 2012. Econometric Analysis (Seventh). New York University.

Jardine, C. G., Gibson, N. and Hrudey, S. E. 1999. Detection of odour and health risk perception of drinking water. Water Science and Technology, 40(6): 91-98.
Levallois, P., Grondin, J. and Gingras, S. 1999. Evaluation of consumer attitudes on taste and tap water alternatives in Québec. Water Science and Technology, 40(6): 135-139.

Mell, I. and Sturzaker, J. 2014. Sustainable urban development in tightly constrained areas: A case study of Darjeeling, India. International Journal of Urban Sustainable Development, 6(1): 65-88.

Nauges, C. and Berg, C. Van Den. 2009. Perception of health risk and averting behaviour: An analysis of household water consumption in Southwest Sri Lanka. Toulouse School of Economics, 1-33.

Onda, K., LoBuglio, J. and Bartram, J. 2012. Global access to safe water: Accounting for water quality and the resulting impact on MDG progress. Int. J. Environ. Res. Public Health, 9: 880-894.

Onjala, J., Ndiritu, S. W. and Stage, J. 2014. Environment for development risk perception, choice of drinking water, and water treatment evidence from Kenyan Towns. J. Water Sanitation and Hygiene for Development, 4(2): 268-280.

Rai, P. 2011. Solid waste management in Darjeeling Municipality. In: M. Desai \& S. Mitra (eds.), Cloud Stone and the Mind: The People and Environment of Darjeeling Hill Area. New Delhi: K. P. Bagchi \& Company.

Serveiss, B. 2002. Applying ecological risk principles to watershed assessment and management. Environmental Management, 29(2): 145-154.

Sharma, P., Ramakrishnan, R., Hutin, Y., Manickam, P. and Gupte, M. 2009. Risk factors for typhoid in Darjeeling, West Bengal, India: Evidence for practical action. Tropical Medicine and International Health, 14(6): 696-702.

Sterling, S. M., Garroway, K., Guan, Y., Ambrose, S. M., Horne, P. and Kennedy, G. W. 2014. A new watershed assessment framework for Nova Scotia: A high-level, integrated approach for regions without a dense network of monitoring stations. Journal of Hydrology, 519: 2596-2612.

Tamang, P. and Jana, S. K. 2017a. Water scarcity in the hill town of Darjeeling: Effects on women's health. Intercontinental Journal of Human Resource Research Review, 5(7): 113-120.

Tamang, P. and Jana, S. K. 2017b. Willingness to pay for improved water services: A case of Darjeeling, India. Asian Journal of Water, Environment and Pollution, 14(2): 51-59.

Turgeon, S., Rodriguez, M. J., Thériault, M. and Levallois, P. 2004. Perception of drinking water in the Quebec City region (Canada): The influence of water quality and consumer location in the distribution system. Journal of Environmental Management, 70(4): 363-373.

UNICEF 2008. Why improved sanitation is important for children. Retrieved from http://www.unwater.org/wwd08/docs/kids-sanitation.pdf

United Nations 2016. Progress towards the sustainable development goals: Report of the Secretary General (Vol. 28564). https://doi.org/10.1017/ S0020818300006640

United Nations Children Fund and World Health Organisation. 2017. Progress on drinking water, sanitation and hygiene - Joint Monitoring Programme 2017 Update and SDG Baselines. In: World Health Organisation. https://doi.org/10.1111 / tmi.12329

Walker, C., Perin, J., Aryee, M., Boschi-Pinto, C. and Black, R. 2012. Diarrhea incidence in low-and middle-income countries in 1990 and 2010: a systematic review. BMC Public Health, 12(220).

WHO and UNICEF 2012. WHO/UNICEF Joint Monitoring Programme (JMP) for Water Supply and Sanitation. Retrieved from https://web. archive.org/web/20120606072534/http://www.wssinfo.org/definitions-methods/introduction/

Wooldridge, J. 2012. Introductory Econometrics: A Modern Approach. South-Western Educational Publishing. 